\title{
IMPLEMENTATION OF SPATIAL INFORMATION FOR MONITORING AND ANALYSIS OF THE AREA AROUND THE PORT USING LASER SCANNING TECHNIQUES
}

\author{
Katarzyna Bobkowska ${ }^{1}$, Adam Inglot ${ }^{1}$, Miroslava Mikusova ${ }^{2}$, Paweł Tysiąc $^{\star 1}$ \\ ${ }^{1}$ Gdansk University of Technology, Poland \\ ${ }^{2}$ Univeristy of Zilina, Slovakia \\ * (corresponding author)
}

\begin{abstract}
Nowadays, maritime infrastructure is heavily exploited, which requires monitoring. The article presents the implementation of spatial information which are point clouds for monitoring and analysis of the area around the port (buildings and wharves). For this study, point clouds coming from terrestrial (TLS) and airborne laser scanning (ALS), each of them having different accuracy, were used. An important part of the analysis was the integration of the two data sources. Through integration, the acquisition of information on areas not covered by the measurement in the presented case, one of the methods was possible for use (e.g. the roofs in case of TLS, or the lack of some of the walls of buildings in case of ALS). Another aspect was to use this data. Measurement of the shape and geometry of objects was executed. Additionally, the planeness analysis of individual elements of port infrastructure has been carried out. An interesting analysis was to determine the water level, based on relation to specific characteristics of the light reflectance.
\end{abstract}

Keywords: spatial information, monitoring of the area around the port, terrestrial and airborne laser scanning

\section{INTRODUCTION}

The Motlawa is a Polish river, which runs in the Pomerania province. This river is a tributary of the Dead Vistula, which has its estuary to Gdansk Bay. Motlawa in Gdansk has a very rich port history. Since the middle ages it was a very important point for the logistics of the Baltic shipping routes. A storage district was located in the vicinity. Wood, grain, iron, copper, lead, wax, leather, fur, eastern roots, cloth, herrings and salt were trans-shipped in the Motlawa Port. Today, this part of Gdansk is usually associated with a tourist attraction of the city. The most popular of them is the Long Bridge. The Motlawa Port functioned until 1939. Currently, Matlawa is a harbor for the cruise company - Żegluga Gdańska - ships. Figure 1 shows the map section of the old Motlawa Port area. Figure 2 shows the same field section of orthophoto map, which was developed in 2014. Due to historical aspects, it is important to archive and inventory all historic buildings. Here, laser and optical scanning is applicable. An example of such a construction in the area of the coast of the Motlawa is a wooden crane, which was first used in 1363. In the past, it was the strongest crane in northern Europe ${ }^{1}$. Besides the advantage of scanning - the ability to archive practically the majority of information on the shape of any object - many other possibilities for the use of scanning port infrastructure can be indicated. These possibilities are discussed further in this article. From today's point of view, they are very important aspects of port building safety. Based on laser scanning, port security systems can be developed, which are just as important to the security systems of ships in the harbor ${ }^{2}$. Due to the floods occurring in the history of Gdansk (in 1540 the Granary Island was completely flooded), monitoring the water level is quite important. Besides monitoring the water level in the river, monitoring the technical condition of the buildings is also necessary. All kinds of cracks, deformation and tilt, should be detected as soon as possible in order to secure and eliminate the total destruction of objects. It is possible to monitor these values by using innovative measurement technologies like laser scanning and create an application 
which could inform the user when the deformations reach critical levels. Scientific research on the border of the water and the ground are not widely implemented and the results are not commonly in use.

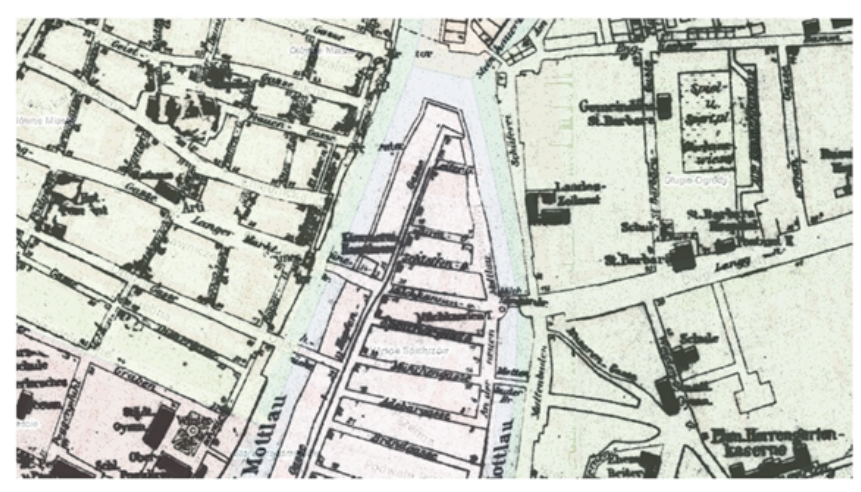

Fig. 1. The Gdansk map section originating from 1940. Area: The Motława around Granary Island.

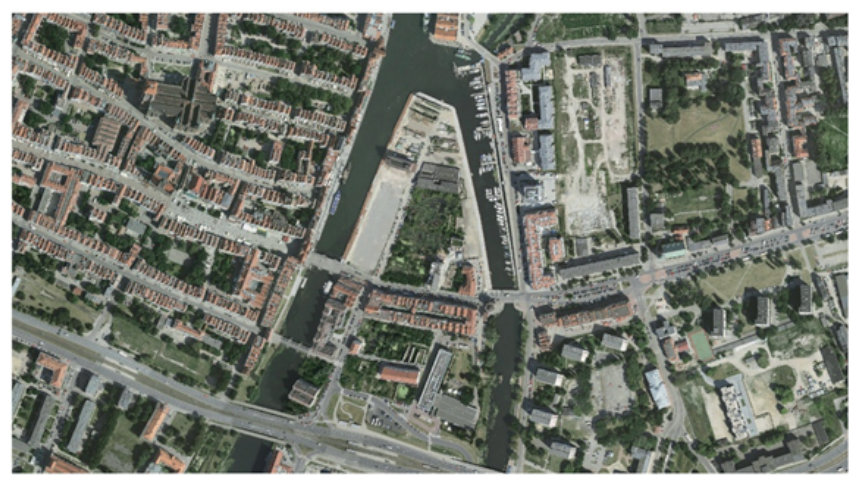

Fig. 2. The Gdansk orthophoto map section originating from 2014 Area: The Motława around Granary Island.

\section{LASER SCANNING AS THE SOURCE OF SPATIAL DATA}

Laser scanning is an efficient tool for gathering spatial information as well as it supports geodetic data in GIS applications and provides support for city modelling ${ }^{3}$. In addition to ranging, Light Detection and Ranging (LiDAR) systems can provide additional information about the target and information about the transmission path ${ }^{4,5}$. To gather the spatial data, two of the laser scanning systems (terrestrial and airborne laser scanning) have been used. Furthermore, based on laser scanning measurements it is an obligation to regard the influence of the heat caused by insolation and vibrations interference. ${ }^{6}$ On the base of collected data, a model of the harbor was created. It was used for monitoring the area of interest by analyzing the utility of proposed applications, which are described below.

To create a point cloud, terrestrial and airborne laser scanning has been used. The results of used point clouds have been shown in Fig. 3 and Fig. 4.

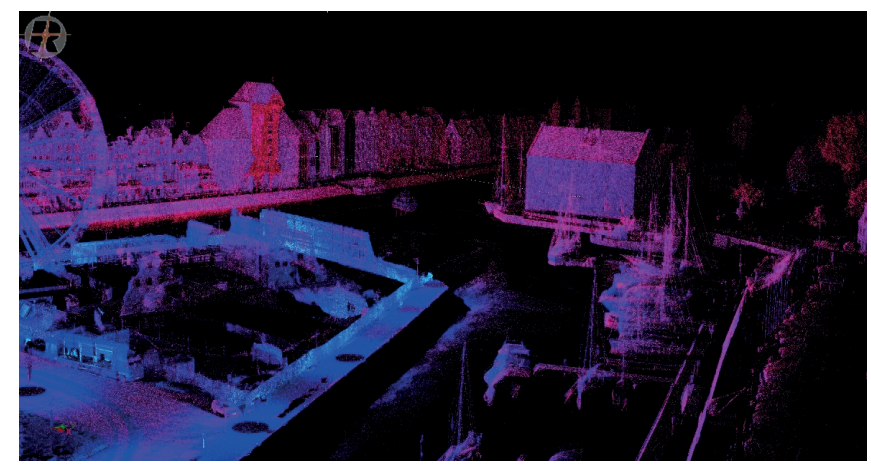

Fig. 3 The results of TLS data acquisition.

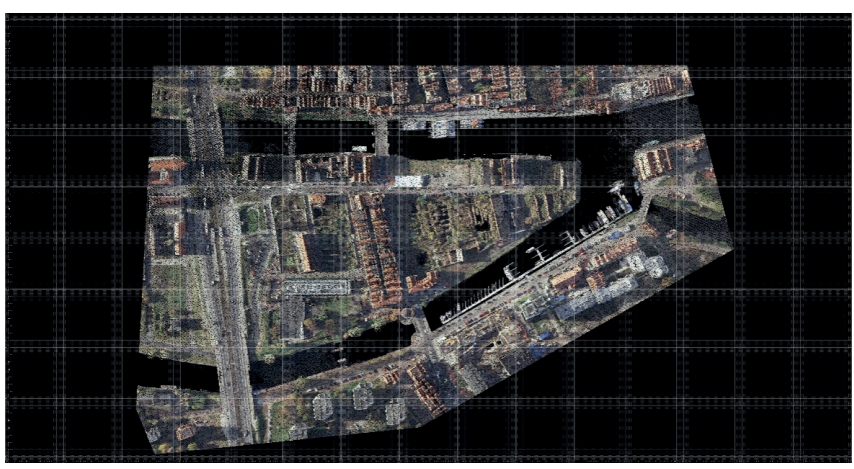

Fig. 4 Visualization of ALS data.

The accuracy of the spatial data, which has been used in the current project is on the level of $5 \mathrm{~mm}$ in reference to TLS in the case of scan positions alignment. The results of data alignment of the TLS are shown in Fig. 5.

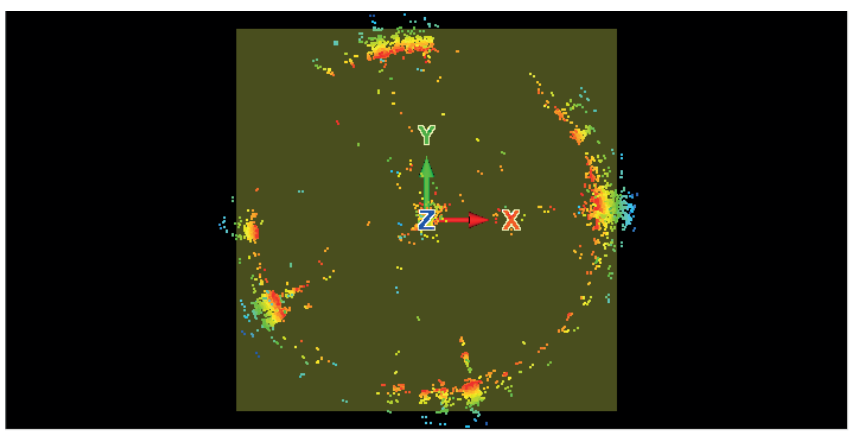

RESIDUES

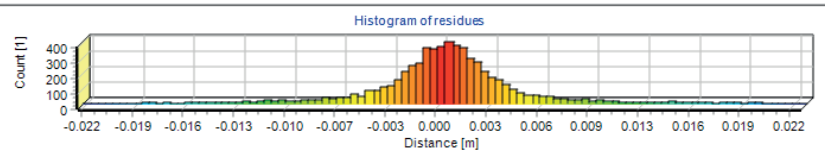

Fig. 5 The results of TLS data alignment.

The accuracy of the ALS data is up to $50 \mathrm{~cm}$ based on the information, provided by Head Office of Geodesy and Cartography. ALS point cloud basic operations of integration of the data which has been used come from the ISOK project. The Polish ISOK abbreviation translates into "IT System of the Country's Protection against hazards". It is aimed at 
providing a system that improves the protection of Economy, Environment and Society against extraordinary threats, especially against flooding ${ }^{8}$.

The point cloud is obtained from TLS measurements which were made on the basis of measurements of 20 positions. In order to connect the following stations geodetic prisms, spheres reference or details of terrain, clearly identifiable on the scan were used. In the case of measurements it was important to give georeferencing because of ALS data integration. For this purpose, measured geodetic Global Navigation Satellite Systems (GNSS) receivers were used. Control points were determined by the $3 \mathrm{D}$ error which was no greater than $0.05 \mathrm{~m}$. In the process of measurements of the coastal zone, places where the horizon is too much obscured should be considered. It has a direct impact on the accuracy of the designated points of geodetic control network using the GNSS receiver ${ }^{9}{ }^{10}$.

The prepared laser data were subjected to further processing that was foremost based on a proper integration of TLS and ALS data. There are two main methods of integration of the data and both of them rely on the user's supervision. The first one is to create tie points, which could be used to reference the data. Whereas the latter is to align the data using temporary tie points and manually create tie planes which are utilized for automatic search for corresponding planes exploiting iterative closest points algorithm (ICP). This algorithm is based on detecting the closest planes in relative data sets and matching them. To create automatic planes the "Plane Patch Filter" has been used, implemented in RiScan Pro, courtesy of Riegl GmbH. "Plane Patch Filter's" basis is to divide the $3 \mathrm{D}$ space into equally sized cubes. For each cube the plane is estimated using least squares method, when the standard deviation of the plane is higher than the assumed value, the cube is further divided into further eight smaller cubes, and the process is repeated. The smallest size of a cube is defined by the user. If the standard deviation is less than expected, the algorithm saves the plane and takes it into consideration during the final alignment process. Based on these algorithms, the ALS and the TLS point clouds have been aligned. The results are shown in Fig. 6.

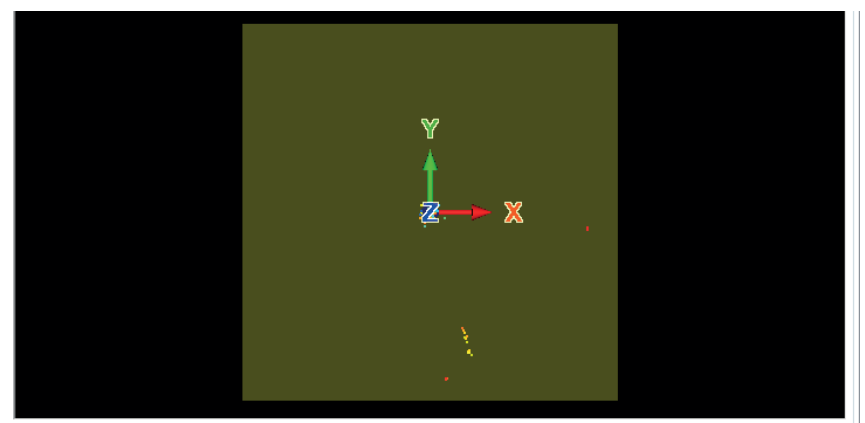
RESIDUES

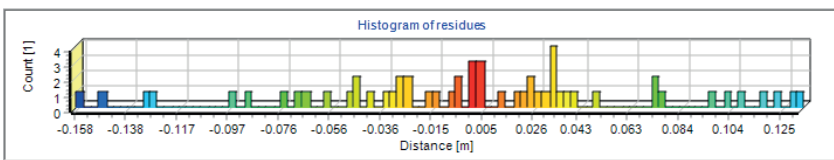

Fig. 6 The results of TLS and ALS alignment.
Based on the conclusive data set, the authors moved on to the analysis in terms of port infrastructure with monument elements. Besides laser scanning, an interesting form to obtain data of objects is optical scanning ${ }^{11}$. It is being used increasingly in the analysis of building shapes and in the analysis of shape changes over time. Optical scanning is a method involving the acquisition of data on the object based on the captured images ${ }^{12}$. Using the methods of photogrammetry, we can pinpoint the coordinates (in local or global system - global requires input data with the coordinates of the markers) characteristic points of the object by two images of the same object. By automating the image processing we are able to quickly obtain very dense and accurate point cloud objects. Regarding to optical or laser scanning measurements the appropriate kind of the platform should be considered. In the project, the authors used a tripod for TLS, but it is possible to acquire data by using a platform on a moving vehicle which could be called as mobile $\mathrm{e}^{13,14,15}$.

\section{POSSIBLE APPLICATIONS OF HARBOR INFRASTRUCTURE ANALYSIS USING INTEGRATED POINT CLOUD}

\section{VISUALIZATION + GEOMETRY}

In the case of visualization, that could be supported with geometry analysis, like the one shown in Fig. 7 (laser scanning method provides metric system with accuracy at the level of a few $\mathrm{mm}$ for TLS, whilst for ALS the accuracy reaches approx. $20 \mathrm{~cm}$ ) the application using integrated point cloud could help establish the boundaries of the safe investments zone or retreat of infrastructure facing real threats such as the degradation of the objects of interests, by creating a warning system from collected data ${ }^{16}$. TLS gives the possibility to analyze the geometry of the various objects (e.g. silos ${ }^{17}$, shell structures, coastal cliffs ${ }^{18}$ ).

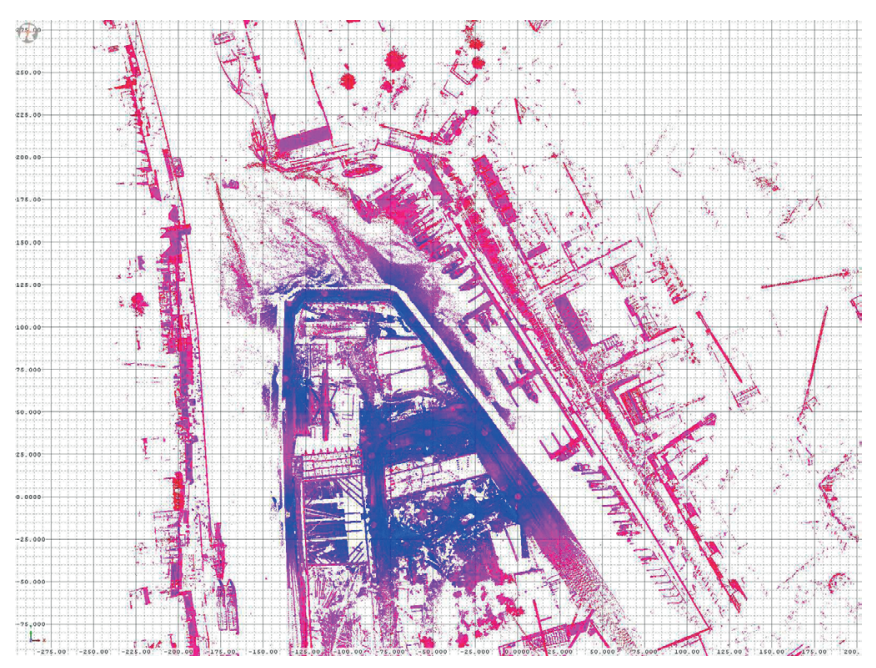

Fig. 7 Plan of the Granary Island, Gdansk with the metric grid, where side length of the square is $5 \mathrm{~m}$. 


\section{ESTIMATE THE WATER LEVEL USING TERRESTRIAL LASER SCANNING}

The estimation of the water level based on terrestrial laser scanning could be executed with specific characteristics of the light reflectance. Reflectance, sometimes called the " $4^{\text {th }}$ coordinate" beside $\mathrm{X}, \mathrm{Y}, \mathrm{Z}$, is the ratio of the reflected beam to the power of the incident light fraction, described on the boundary of two media with different refractive coefficients, expressed in decibels with a negative sign ${ }^{19}$. In the case of the described application, the value of the amplitude has been used. The amplitude is known as the intensity of reflection. Relying on the fact that water absorbs the infrared part of the electromagnetic spectrum(the amplitude equals 0 ) the operator could with high precision point out the place of water level by using adjacent harbor infrastructure. There was a distinctive boundary, a "cut off" where there were no valid points (reflections) on vertical walls (i.e. Larssen sheet piling). Also, one could accurately estimate the height of the water level according to the measurements conducted in relation to the national vertical reference system. The chart presenting reflection from different type of targets is shown in Fig. 8. There is a line, marked with no. 7, corresponding to remote sensing windows for water as an optical medium.

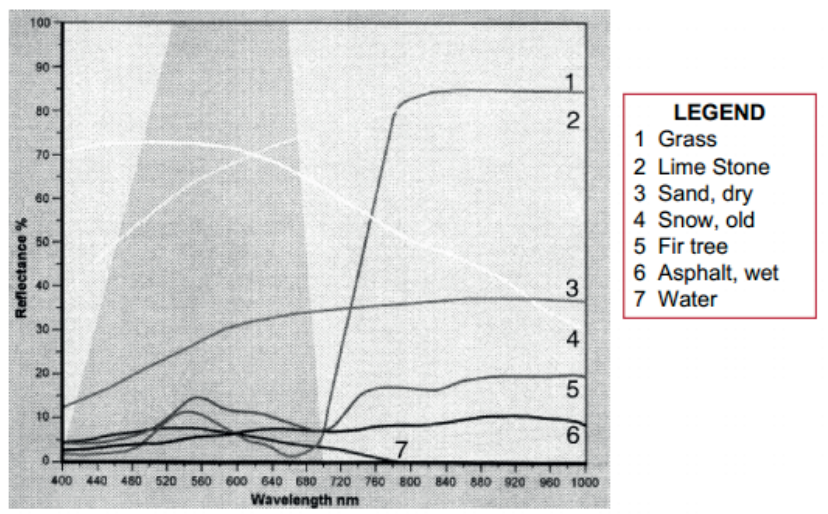

Fig. 8 Reflectance of different types of targets [3].

To precisely point a place where a water level appears, the user has to find a row of points where the amplitude of these hits is approximately $1 \mathrm{~dB}$. What is more, to avoid misinterpretation, the operator should check for the close neighbourhood of the marginal air-water laser scanning reflexes. Those should have an amplitude value of no more than a few $\mathrm{dB}$, in this case: 6-7 dB. The example of water level estimation is shown in fig. 9. The acquired data can also help to gather information on the level of the seabed, in the case of shallow areas. For greater depth, other methods should be used. ${ }^{20},{ }^{21}$ for example: acoustic waves are widely used ${ }^{22}$.
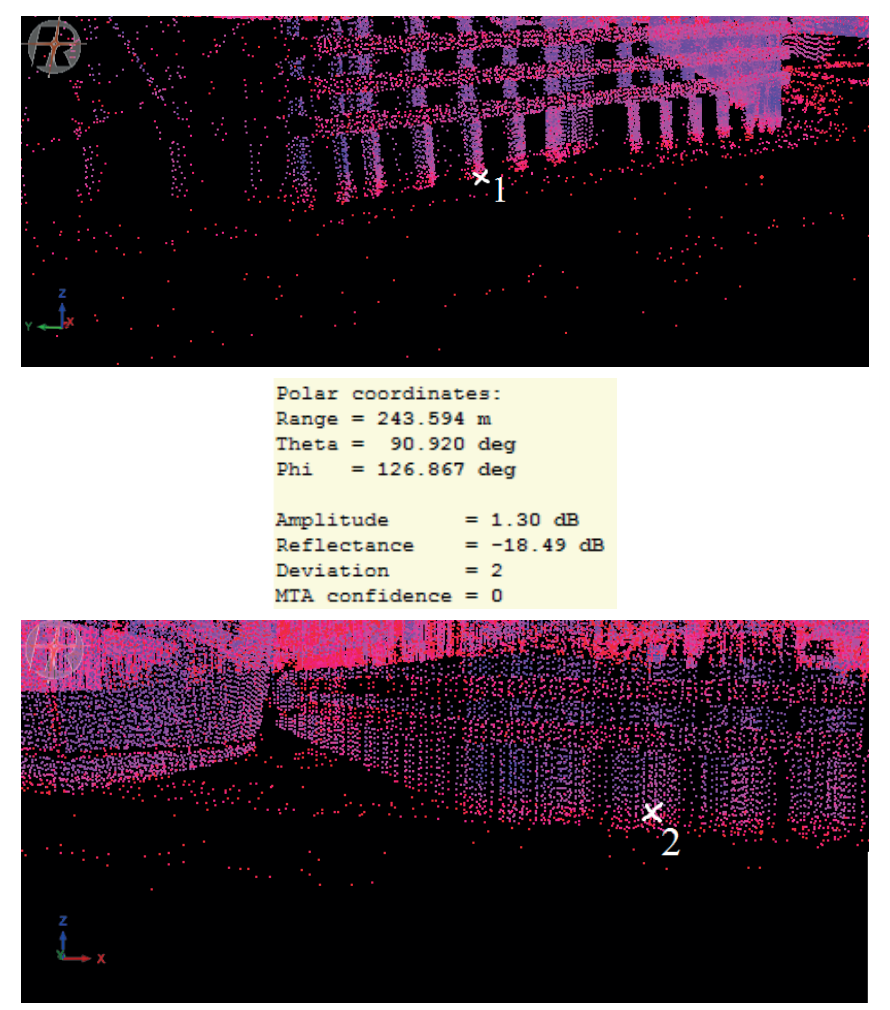

Polar coordinates:

Range $=243.157 \mathrm{~m}$

Theta $=90.940 \mathrm{deg}$

$\mathrm{Phi}=126.427 \mathrm{deg}$

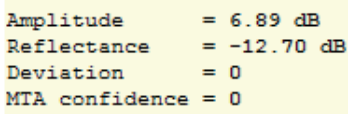

Fig. 9 Water level estimation, based on amplitude characteristic.

\section{HARBOR INFRASTRUCTURE MONITORING}

Laser scanning datasets as a source for infrastructure monitoring could be very useful in the evaluation of stability and degradation level of the harbor. This method is based on creating a $3 \mathrm{D}$ triangulated model. With this method the operator could easily estimate the wall inclination or deviation of any other type of element. This applies as much to planar structures as for linear objects. In fig. 10 the authors have shown an example of wharf deviation from assumed plane. The different colors indicate local displacement from a horizontal position.

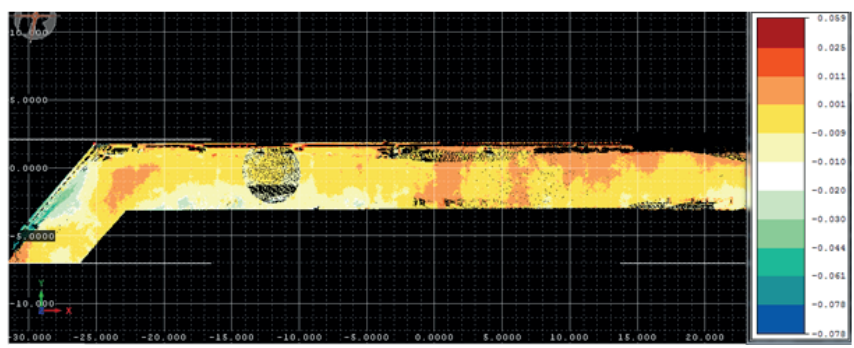

Fig. 10 Inclination from horizontal position of the wharf. 
Due to laser scanning limitations such as the inability to penetrate the structure with a light beam, the degradation monitoring can only be a guide to true object's condition. Dense point clouds are subject to search for major defects: missing, buckled or dented elements, cracks (also tiny ones) and abrasions. The crack detection was further presented in the paper ${ }^{23,24}$. The operator can only rely on geometrical characteristics of the monitored object, though it is still very precise and effective information on general structural integrity. The result of such monitoring can be easily compared with some reference data (CAD drawings, original inventory surveys). Hand in hand, with the addition of more complex GIS analysis of cracks or displacements, the operator could be provided with an advanced failure prediction.

\section{CONCLUSIONS AND DISCUSSION}

The article briefly presents the spatial analysis of former Polish Motlawa Port, which today is an important tourist attraction of the city of Gdansk. Due to historical buildings located in in this area, archiving residues of these objects requires a specific approach. The solution to this problem can be achieved using the methods of photogrammetry and remote sensing ${ }^{25}$, and specifically speaking - laser scanning. The presented feasibility of collecting data on these objects and their visualization, have great potential today. Collected data on the Granary Island and surrounding areas may serve as an interesting informant in the future. Besides archiving for the purpose of data visualization, special attention was paid to the safety aspect. Areas around the port, due to contact with water, are more susceptible to the phenomenon of destruction. The method that allows the analysis of vertical and planeness waterfront has been presented. A deviation map presented in this article was created based on data from laser scanning. This map indicates the location where there are deviations from the plane of the waterfront wall. The presented analysis can be carried out for the needs of other facilities around ports in Poland and in the world.

\section{ENDNOTES}

1. http://www.nordstern-gdansk.cba.pl/Port\%20Gdanski/ gdansk\%20port\%20nad\%20motlawa.html

2. Szlapczynski, R., Szlapczynska, J.: On evolutionary computing in multi-ship trajectory planning, Appl Intell 37: 155, 2012, DOI:10.1007/s10489-011-0319-7

3. Tse R.O.C., Gold C., Kidner D.: 3D City Modelling from LIDAR Data. In P. Van Oosterom et al., eds. Advances in 3D Geoinformation Systems. Springer Berlin Heidelberg, pp. 161-175, 2008

4. Introduction to LIDAR, NPS Lidar Workshop, May 24, 2007, Joe Liadsky, Optech Incorporated.
5. Wehr A., Lohr U.,. Airborne laser scanning--an introduction and overview. ISPRS Journal of Photogrammetry and Remote Sensing, Vol. 54, Iss. 2-3, pp.68-82, 1999

6. Kaliński K. J., Galewski M. A. Kaliński K. J., Galewski M. A.: Chatter vibration surveillance by the optimallinear spindle speed control. Mechanical Systems and Signal Processing, Vol. 25, pp. 383-399, 2011, DOI: 10.1016/j.ymssp.2014.06.016

7. Kersten T, et al: Geometric accuracy investigations of the latest terrestrial laser scanning systems. FIG Working Week, (June), pp.1-16, 2008

8. Pawłuszek K., Ziaja M., Borkowski A.: Accuracy Assessment of the Height Component of the Airborne Laser Scanning Data Collected in the ISOK System for the Widawa River Valley. Acta Scientiarum Polonorum. Geodesia et Descriptio Terrarum, Vol. 13, pp.27-37, 2014

9. Tysiac, P., Wojtowicz A., Szulwic J.: Coastal Cliffs Monitoring and Prediction of Displacements Using Terrestial Laser Scanning. Baltic Geodetic Congress (Geomatics), IEEE, ISBN: 978-1-5090-2421-6, pp. 61-66, 2016, DOI: 10.1109/BGC.Geomatics.2016.20

10. Grejner-Brzezinska D.A., et al.: A robust solution to highaccuracy geolocation: Quadruple integration of GPS, IMU, pseudolite, and terrestrial laser scanning. IEEE Transactions on Instrumentation and Measurement, Vol. 60, Iss.11, pp.3694-3708, 2011

11. Paszotta, Z., Szulwic, J., Szumilo, M.: Internet photogrammetry as a tool for e-learning. 8th International Conference of Education, Research and Innovation, ICERI2015, ISBN: 978-84-608-2657-6, pp. 4565-4573, 2015

12. Bobkowska, K., Janowski, A., Przyborski, M. and Szulwic, J.: Analysis of High Resolution Clouds of Points as a Source of Biometric Data, 2016 Baltic Geodetic Congress (Geomatics), Gdansk, 2016, ISBN: 978-1-5090-2421-6, pp. 15-21, DOI: 10.1109/BGC.Geomatics.2016.12

13. Kalinski K., Buchholz C.: Mechatronic design o strongly nonlinear systems on a basis of three wheeled mobile platform. Mechanical Systems and Signal Processing, Vol. 52-53, pp. 700-721, 2015, DOI: 10.1016/j.ymssp.2014.06.016

14. Mikrut, S., Kohut P. et al.: Mobile Laser Scanning Systems for Measuring the Clearance Gauge of Railways: State of Play, Testing and Outlook. Sensors, Vol. 16, Iss. 5, pp. 683, 2016, DOI: $10.3390 /$ s16050683

15. Pastucha, E.: Catenary System Detection, Localization and Classification Using Mobile Scanning Data. Remote Sens. Vol. 8, Iss. 801, 2016, DOI: 10.3390/rs8100801. 
16. Burdziakowski P., Janowski A., Kholodkov A. Matysik K., Matysik M., Przyborski M., Szulwic J., Tysiac P.: Maritime laser scanning as the source for spatial data. Polish Marit. Res., Vol. 22, Iss. 4, pp. 9-14, 2015, DOI: 10.1515/ pomr-2015-0064

17. Gorski J., Mikulski T., Ozieblo M., Winkelmann K.: Effect of geometric imperfections on aluminium silo capacities. Stahlbau. Vol. 84, Iss. 1, 2015, pp. 52-57, DOI: 10.1002/ stab.201510224

18. Rohmer J. and Dewez T.: Analysing the spatial patterns of erosion scars using point process theory at the coastal chalk cliff of Mesnil-Val, Normandy, northern France. Nat. Hazards Earth Syst. Sci., Vol. 15, pp. 349-362, 2015, DOI: 10.5194/nhess-15-349-2015

19. Höfle B., Pfeifer N.: Correction of laser scanning intensity data: Data and model-driven approaches. ISPRS Journal of Photogrammetry and Remote Sensing, Vol. 62, Iss. 6, pp.415-433, 2007

20. Kozaczka E., Grelowska G., Kozaczka S.: Images of the seabed of the gulf of gdansk obtained by means of the parametric sonar. Acta Physica Polonica A. Vol. 118, no.1 s.91-94, 2010

21. Grelowska G., Kozaczka E.: Underwater Acoustic Imaging of the Sea. Archives of Acoustics. Vol. 39, no. 4, pp. 439-452, 2014, DOI: 10.2478/aoa-2014-0048

22. Rucka M., Wilde K.: Experimental study on ultrasonic monitoring of splitting failure in reinforced concrete. Journal of Nondestructive Evaluation. Vol. 32, Iss. 4, pp.372-383, 2013, DOI: 10.1007/s10921-013-0191-y

23. Nagrodzka-Godycka K., Szulwic J., Ziolkowski P.: The method of analysis of damage reinforced concrete beams using terrestrial laser scanning. 14th International Multidisciplinary Scientific GeoConference, International Multidisciplinary Scientific GeoConference \& EXPO SGEM, ISBN: 978-619-7105-12-4 / ISSN: 13142704, Book 2, Vol. 3, pp. 335-342, 2014, DOI:10.5593/ SGEM2014/B23/S10.042

24. Janowski A., Nagrodzka-Godycka K., Szulwic J., Ziolkowski P.: Remote sensing and photogrammetry techniques in diagnostics of concrete structures. Computers and Concrete, Vol. 18, Iss. 3, pp. 405-420, 2016, DOI: 10.12989/cac.2016.18.3.405

25. Tong X., et al.: Integration of UAV-based photogrammetry and terrestrial laser scanning for the three-dimensional mapping and monitoring of open-pit mine areas. Remote Sensing, Vol. 7, Iss. 6, pp.6635-6662, 2015

\section{CONTACT WITH THE AUTHOR}

Katarzyna Bobkowska

e-mail:katarzyna.bobkowska@pg.gda.pl

Gdansk University of Technology

Faculty of Civil and Environmental Engineering, Department of Geodesy

ul. Narutowicza 11/12, 80-233 Gdansk

\section{Poland}

\section{Adam Inglot}

e-mail: adam.inglot@pg.gda.pl

Gdansk University of Technology

Faculty of Civil and Environmental Engineering,

Department of Geodesy

ul. Narutowicza 11/12, 80-233 Gdansk

\section{Poland}

\section{Miroslava Mikusova \\ e-mail:mikusova@fpedas.uniza.sk}

Univeristy of Zilina, Faculty of Operation and Economics of Transport and Communications, Department of Road and Urban Transport

\section{SlOVAKIA}

\section{Paweł Tysiąc}

e-mail:pawel.tysiac@pg.gda.pl

Gdansk University of Technology

Faculty of Civil and Environmental Engineering, Department of Geodesy

ul. Narutowicza 11/12, 80-233 Gdansk

\section{Poland}

